\title{
PATRIMONIALIZAÇÃO DO CARNAVAL EM MARAGOGIPE-BA: dinâmicas e ambiguidades da cultura ${ }^{1}$
}

\section{PATRIMONIALIZATION OF THE CARNIVAL IN MARAGOGIPE-BA: dynamics and ambiguities of culture}

\author{
Carlos Henrique Cardoso* \\ Fátima Tavares ${ }^{* *}$
}

\begin{abstract}
Resumo
No ano de 2009 o Instituto do Patrimônio Artístico Cultural (IPAC), órgão do Governo do Estado da Bahia, oficializou o registro do carnaval de Maragojipe como patrimônio cultural imaterial/intangível. Desde então observam-se algumas transformações da festa local, além do surgimento de eventos fora do período carnavalesco, realizados tanto pela gestão municipal quanto por entidades não-governamentais, intensificando e ressignificando a circulação de elementos daquela festa, especialmente os "mascarados" (ou "caretas", na designação nativa), para novos contextos. Neste artigo buscamos compreender duas questões que nos parecem importantes: 1) entender como se deu o processo de patrimonialização do carnaval de Maragojipe; e 2) identificar alguns dilemas e reconfigurações subsequentes a esse processo, em busca de compreender como a figura do "mascarado", que é o símbolo principal do carnaval, se projeta para além da festa e invade outros setores da vida e da concepção de tempo local.
\end{abstract}

Palavras-chave: Patrimônio imaterial. Festa popular. Carnaval. Máscaras. Caretas.

\begin{abstract}
In the year 2009, the Institute of Artistic and Cultural Heritage (IPAC), an office of the government of the State of Bahia, officially inscribed the Carnival of Maragojipe as part of the immaterial/intangible cultural heritage. Since then, some transformations of the local popular festival have been observed, as well as the occurrence of events outside the carnival time period, carried out both by municipal administration and by non-government entities, intensifying and reframing the circulation of elements typical of that festival, especially "masquerades" to new contexts. In this article we seek to understand two issues that we think are important to know, namely: 1) to understand how the process of patrimonialisation of the Maragojipe carnival took place; and 2) to identify some dilemmas and subsequent reconfigurations of this process, in order to understand how the figure of the "masquerade", which is the main symbol of the carnival, is projected beyond the party itself, into other aspects of the local life and its conception of time.
\end{abstract}

Key-words: Intangible heritage. Popular party. Carnival. Masks. F.

\footnotetext{
1 Este artigo apresenta de forma condensada a questão principal da dissertação de mestrado em antropologia de Carlos Cardoso, defendida em 2016, sob a orientação de Fátima Tavares, pesquisa que contou com o apoio da CAPES. O trabalho de campo foi realizado em 2015, com consulta a fontes escritas (jornais e outros documentos), etnografia do carnaval da cidade naquele ano e realização de entrevistas com brincantes da festa, comerciantes, professores, músicos, servidores públicos da Secretaria de Cultura, com a então secretária de cultura Priscila Mendes e o ex-secretário de Cultura do município, Pedro Arcanjo. Agradecemos as contribuições dos revisores para a forma final deste artigo, com sugestões específicas e teóricas mais amplas.

* Mestre em Antropologia/UFBA. E-mail: chs_cardoso@yhaoo.com.br.

** Professora do Departamento de Antropologia e do Programa de Pós-Graduação em Antropologia/UFBA. E-mail: fattavares@ufba.br
} 
No ano de 2009 o Instituto do Patrimônio Artístico Cultural (IPAC), órgão do governo da Bahia, oficializou o registro do carnaval de Maragojipe como patrimônio imaterial, em solenidade ocorrida durante a festa, com a presença do então governador Jaques Wagner. A solicitação partiu da Secretaria de Cultura daquela cidade, no intuito de preservar o carnaval e torná-lo mais conhecido por visitantes e foliões. Desde então observam-se algumas transformações da festa local, além do surgimento de eventos fora do período carnavalesco, realizados tanto pela gestão municipal, quanto por entidades civis, intensificando e ressignificando a circulação de elementos da festa, especialmente os "mascarados" (ou "caretas", na designação nativa), para novos contextos.

Localizado no Recôncavo Baiano, a 130 km de Salvador, o município de Maragojipe tem sua história ligada ao início da colonização portuguesa, ainda no século XVI, quando uma capela em homenagem a São Bartolomeu foi erguida, iniciando os louvores ao Santo que veio a se tornar padroeiro do lugar, sendo elevada à categoria de Freguesia em 1640, com a denominação São Bartolomeu de Maragojipe (IBGE, 1958) ${ }^{2}$. Com uma população de cerca de 46 mil habitantes, segundo dados do IBGE (2010), o município realiza várias festividades ao longo do ano, dentre estas, as festas juninas, a Festa de São Bartolomeu, em agosto, e o carnaval.

Este artigo busca, em primeiro lugar, retraçar o processo de patrimonialização do carnaval de Maragojipe. Em seguida, apontando alguns dilemas e reconfigurações subsequentes a esse processo. Veremos, também, como o "mascarado", símbolo principal do carnaval, se transforma para além da festa. Como evidencia a abordagem de Perez (2012), devemos compreender a festa não pelo que esta expressa ou representa, mas, sobretudo, por sua capacidade de criação. Articulada a essa ideia, destacamos também as contribuições de Tavares (2012) e Tavares e Bassi (2015) sobre o que a festa "faz", de como transforma o social - no sentido de Latour (2012), como rede provisória de associações -, e não em vez do que a festa "e’” (o que seria a essência da festa?). São abordagens que insistem na proeminência dos processos empíricos das festas, em vez de no lugar de ancorá-las em quadros explicativos que demarcam fronteiras rígidas entre contexto ritual e cotidiano. Seguindo nessa direção, podemos compreender como a patrimonialização do carnaval vem transformando a cultura local, além de fomentar processos que extravasam a festa. Iniciamos com uma breve história do carnaval na cidade. Em seguida, após a apresentação de alguns desafios e dilemas implicados nas políticas de patrimonialização, situamos o caso do carnaval de Maragojipe, problematizando alguns aspectos dessa narrativa de patrimonialização. $\mathrm{Na}$ conclusão, retomamos questões apresentadas ao longo do texto, destacando os movimentos "para dentro" e "para fora" de transformação da festa.

2 Algumas atividades econômicas datam do povoamento europeu como extração de madeira, plantio de cana-de-açúcar e mandioca, com construções de engenho e casas de farinha para processar os produtos cultivados. Após o açúcar e a farinha, o café passou a ter seu ciclo produtivo no município, gerando novos investimentos. Porém, o produto que se tornou fonte de receitas mais duradouro foi o fumo, a partir da instalação das fábricas Suerdieck. Com a falência da fábrica no início dos anos 1990, o setor industrial avançou com a implantação de uma área para construção de plataformas de extração de petróleo e manutenção de equipamentos de suporte para atividades petrolíferas. No início da década de 2010, um polo naval foi inaugurado, mas o projeto encontra-se inativo. 


\section{O Carnaval em Maragojipe}

O entrudo, brincadeira carnavalesca da segunda metade do século XIX, era muito criticada pelos veículos de comunicação no país (MORAES FILHO, 1979). Moura (2013) aponta que a história do carnaval no Brasil se iniciou com o entusiasmo das elites em reproduzir cenários que se assemelhavam aos carnavais europeus, principalmente de Nice, na França, um carnaval disciplinado que viria a substiruir o entrudo, considerado "atrasado". No final do século XIX, o novo modelo de festa provocou o afastamento de batucadas, afoxés e grupos de mascarados nas ruas de Recife, Rio de Janeiro e Salvador.

Fry e colaboradores (1988, p. 243) chamam a atenção para a brincadeira nas ruas do país, resguardando hierarquias sociais enraizadas do cotidiano: "[...] dificilmente negros molestam brancos, enquanto estes atiravam substâncias em negros, sem cerimônia". Os autores descatam, ainda, que com o advento do carnaval passam a ocorrer grandes desfiles e bailes públicos, além da comercialização de máscaras e fantasias. A passagem do entrudo para o carnaval promove, assim, a domesticação da festa. Em Salvador esse processo também teve lugar nas primeiras décadas do século XX:

Hussardos, demônios e arlequins invadem as ruas, desfilando ao som de valsas, marchas e lundus tocados pelas charangas dos grandes clubes. Ao que tudo indica, estes são o ponto alto do carnaval de Salvador. Para sua passagem, enfeitam-se as ruas de vários logradouros e famílias que moram em lugares fora de seu intinerário, escrevem castas aos jornais pedindo que o préstito percorra suas ruas. A administração pública incentiva a realização dos festejos propiciando uma estrutura mínima: controla mudança de intinerário [...] ilumina e decora ruas centrais da cidade pelos quais percorrerá os préstitos, etc. (FRY et al., 1988, p. 247-248).

Acompanhando essas transformações, foi justamente nas primeiras décadas do século passado que surgiram os mascarados do carnaval maragojipano, que também abrigou em suas ruas as brincadeiras do entrudo ${ }^{3}$. Além da caracterização de diversos foliões mascarados, ocorriam bailes carnavalescos nos clubes sociais da cidade, a Rádio Clube ${ }^{4}$ e a Associação Atlética $^{5}$, cujo período áureo se estendeu até o fim dos anos 1980. Os bailes eram regidos pelas filarmônicas "Terpisicore" e "Dois de Julho", sediadas no município, além de grupos musicais e "jazes" (pequenos conjutos musicais). O baile de carnaval não era um divertimento apenas

\footnotetext{
3 Essa memória da festa foi destacada por nossos interlocutores de pesquisa, sendo também encontrada em diversas notícias de jornal, e devidamente registrada no Cadernos do Ipac sobre o carnaval de Maragogipe (BAHIA, 2010). 4 A Rádio Clube era administrada por indivíduos de origem germânica que lá se reuniam para jogos e reuniões diversas e que no carnaval abriam o espaço para a sociedade maragojipana bailar suas marchinhas e demais canções apropriadas para a festa, no espaço reservado na sua sede situada na Rua do Porto.

5 Local onde atualmente funciona a Fundação Vovó do Mangue, organização socioambiental com inúmeros trabalhos voltados não apenas para a atividade pesqueira, mas também para dar apoio a apresentações de grupos de capoeira. O local abriga a Associação dos Sambadores e Sambadeiras da cidade, um infocentro, uma quadra poliesportiva e um amplo espaço para a realização de cerimônias e bailes carnavalescos.
} 
da população abastada, como esclarece um entrevistado: "Havia a Rádio Clube e a Associação Atlética onde os grupos tocavam. Enquanto um tocava pro pessoal mais abastado, o outro tocava pra operários, trabalhadores" 6 .

Conforme veremos mais adiante, o diferencial do carnaval maragojipano está no "mascarado" (fantasia com máscara, também chamada de "careta"). Na memória local enfatizase que estes sempre estiveram presentes na festa, que costuma ser comparada ao carnaval veneziano (alguns moradores, inclusive, citaram esse famoso carnaval como inspiração para as máscaras que atualmente desfilam no carnaval da cidade). No passado, as máscaras eram bem diferentes das atuais, sendo marcadas pela simplicidade das formas e materiais: sacos de cimento, de farinha, de linhagem, entre outros. Um interlocutor, professor com grande conhecimento sobre a história do município, teceu considerações sobre esse processo de confecção:

As máscaras eram feitas de papel colado, saco de cimento, saco de farinha de trigo, qualquer material de embalagem. Deixava de ser ele pra virar um personagem da festa que é contagiosa em todos os aspectos. Então isso faz a espontaneidade do carnaval de Maragojipe em consequência das suas dificuldades econômicas que deu margem ao cotidiano, já que temos a nossa festa maior que é a de São Bartolomeu, temos o carnaval e o São João, sendo que o carnaval era a que dava maior oportunidade pra brincar, pois se ele não tivesse nada pra se fantasiar, ele chegava no mangue e se lambuzava todo de lama...Ainda tem quem faça isso hoje, e vem pra praça todo sujo de lama pra não perder a oportunidade de participar do carnaval.

Com o passar dos anos, as máscaras ganharam novas feições, como a "narigueta", máscara de chifre, muito popular, além das mais "estilosas", de porcelana, que muitos associam ao carnaval veneziano. Na cidade, alguns artesãos dão continuidade à feitura desses artigos essenciais para os brincantes: apesar das dificuldades em passar seus conhecimentos aos mais jovens, eles mantêm o ofício.Figura 1 - Figura 2 -

Nos anos de 1950, acompanhando as transformações do carnaval soteropolitano, também o carnaval de Maragojipe incorporou a apresentação de trio elétrico na festa. Aidil do Nascimento, o "Dica", foi o idealizador do trio "Maragós", que ocasionalmente ainda desfila durante o carnaval. Esse veículo tornou-se uma referência para os moradores, que lamentavam quando o mesmo não estava presente na folia maragojipana. Ao retornar à cidade após exibição em outro município, o trio tocava para o público, que solicitava aos músicos a execução de frevos para "matar a saudade" (na quarta-feira de cinzas ou outro dia após o período carnavalesco). Na década de 1980, o trio da banda local "Transas Mil” também passou a desfilar, sendo sempre acompanhado por grande multidão. Formado em 1984, esse trio surgiu quando o ritmo axé music começava a divulgar seus primeiros sucessos. A banda compôs dois grandes hits do período: “Beijo na Boca” e "Força do Ilê". Em 1986, o “Tansas Mil” desfilou em seu próprio trio 
pelas ruas de Maragojipe, conduzindo centenas de foliões. Esse gênero musical consolidou o movimento de "reprodução" do carnaval soteropolitano, com blocos criados para acompanhar o trio elétrico. Até o início dos anos 2000 esse modelo de carnaval se mostrou presente. Os mascarados, no entanto, não deixavam de aparecer na festa, seguindo os trios elétricos com suas típicas indumentárias.

A partir dos anos 1990 ocorre uma maior participação da gestão municipal na contratação de músicos para se apresentar ao palco construído na praça central da cidade, reduzindo, assim, a circulação dos brincantes pelas ruas. Na fase atual do carnaval maragojipano vão se consolidando as manifestações "estáticas" da folia, visto que as bandinhas que outrora desfilavam pelas ruas começam a subir ao palco, diminuindo o número de músicos (e consequentemente, os custos da apresentação). Em tempos idos, grupos de samba de roda, blocos afro, além das tradicionais charangas, movimentavam as ruas do município. A confluência desses grupos na rua, numa miscelânea de estilos musicais circulando e se encontrando pelas vias da cidade, possivelmente facilitava uma maior interação entre os brincantes e mascarados.

$\mathrm{Na}$ configuração musical da festa predominam, atualmente, as marchinhas executadas pelas charangas, compostas por músicos de filarmônica que se reúnem de forma independente, grupos que há décadas arrastam multidões pelas ruas da cidade. Muitos desses músicos se reúnem na Orquestra Popular de Maragojipe, que acompanha procissões religiosas, além de executar baiões e xotes durante festas juninas e marchas carnavalescas, sendo, portanto, uma formação especial que se encontra em variados eventos da vida comunitária do município. São esses grupos musicais que iniciam a festa, tocando suas versões de clássicos carnavalescos no período matutino, quando os primeiros mascarados e fantasiados aparecem nas ruas de Maragojipe.

Outra manifestação típica do carnaval da cidade é o "Bloco das Almas" (também chamado de "Bloco do Silêncio"). São pequenos grupos de fantasiados mascarados - usualmente vestidos de branco - que desfilam pelas ruas durante a madrugada de sexta para sábado de carnaval, simulando assombrações e utilizando correntes, velas, tambores e outros apetrechos em suas andanças. Esses grupos costumam iniciar seu trajeto em frente ao cemitério municipal para se encontrar na Praça Matriz da cidade.

Mas as transformações do carnaval ao longo do século passado implicaram o desaparecimento de certas manifestações como o Bumba Meu $\mathrm{Boi}^{7}$ e a Burrinha ${ }^{8}$, que compunham o cenário do carnaval maragojipano, além de marcar presença nos Ternos de Reis do município9. Já houve em Maragojipe oficinas de confecção da Burrinha e do Bumba Meu

7 Esta manifestação, segundo depoimentos, era muito frequente nos dias de festa. As origens do Bumba Meu Boi são muito antigas e estão vinculados à expansão da criação de gado na região nordeste. Cf. Cascudo (2001).

8 A Burrinha é mais uma manifestação que apresenta a figura alegórica do animal bastante disseminado na zona rural de municípios baianos, sendo destacada em propaganda turística do governo do estado, como em http://www. visiteabahia.com.br/visite/atracoes/folclore/burrinha.php Acesso em: 05 ago. 2015.

9 Festa popular presente em Salvador e em vários municípios do entorno da Baía de Todos os Santos. Sobre a festa 
Boi, justamente para perpetuar a brincadeira durante os festejos do carnaval. Porém, segundo ex-funcionários da Casa de Cultura da cidade, o projeto não teve continuidade.

Especialmente lembrados em conversas com nossos interlocutores foram os grupos de "batucada" que desfilavam pelas ruas. Eram grupos de amigos que se reuniam para tocar instrumentos de percussão. Dois deles foram especialmente referidos: "Raízes da Terra" e "Levada da Paz" (o "Raízes da Terra" continua se apresentando no palco, porém, com menos componentes). Também aconteciam desfiles de agremiações como o afoxé "Apalache" (que saía de um terreiro de candomblé), além de grupos de samba de roda, que desfilavam pelas ruas.

\section{A patrimonialização do Carnaval}

As políticas de patrimonialização assentam-se em referências históricas de uma certa "tradição", por meio de documentos escritos e de relatos da comunidade que fundamentam processos de Tombamento (patrimônio material) e Registro (patrimônio imaterial), além do desenvolvimento de medidas de salvaguarda. O patrimônio legitima a cultura local - "um legado coletivo de indivíduos", como afirmam Abreu e Lima Filho (2007, p. 40) - por via da memória, situando os atores sociais como protagonistas do processo (ROCHA; ECKERT, 2010).

Gonçalves (2012) destaca que desde a década de 1990 observa-se um alargamento da noção de patrimônio, movimento que está relacionado a alguns fatores: a) do ponto de vista institucional, o Estado brasileiro já não detém a exclusividade de sua identificação, que se dispersa por muitas iniciativas da sociedade; b) transformações na esfera discursiva, com reivindicação das memórias locais; c) intensificação das relações entre patrimônio e turismo ${ }^{10}$. Outrora solene e consensual (dada a hegemonia do Estado nessas políticas), o patrimônio se "democratizou".

Mas, apesar da intensificação do uso dessa categoria, Gonçalves (2005) pondera que o patrimônio resulta não apenas de decretos ou vontades de indivíduos ou grupos, mas precisa ter ressonância entre os diferentes segmentos envolvidos, evocando poderes e sensibilidades que se

em Salvador, ver Ramos (2017); sobre as variações do Terno de Reis numa comunidade do município de Simões Filho, cuja festa é conhecida como "Queimada da palhinha", ver Silveira (2015).

10 O processo de valorização dos patrimônios nacionais foi reconhecido pela UNESCO, em 1972, como patrimônio cultural. No caso brasileiro, a Constituição de 1988 estabelece, no artigo 215, que "o Estado protegerá as manifestações das culturas populares, indígenas e afro-brasileiras e das de outros grupos participantes do processo civilizatório nacional"; no artigo 216 enumera os bens de natureza material e imaterial a serem protegidos pelo Estado (BRASIL, 1988). As políticas de salvaguarda do patrimônio ganharam incremento com o passar dos anos, garantindo a criação de outras resoluções e instituições de conservação dos bens culturais. O Decreto n 3.551 , de 4 de agosto de 2000, constitui o Registro de Bens Culturais de Natureza Imaterial que garante o reconhecimento de políticas voltadas para o patrimônio imaterial e configura o conceito de "Registro" dos bens nos seguintes Livros: saberes (modos de fazer); celebrações (festas, rituais); formas de expressão (manifestações literárias, musicais, plásticas); lugares (espaços onde as práticas são executadas). O Instituto do Patrimônio Histórico e Artístico Nacional (IPHAN), órgão responsável pela patrimonialização em nível nacional, também determinou que cada registro a ser pesquisado terá que seguir uma metodologia instituída pelo órgão. A institucionalização de um patrimônio intangível vigora então sob certos critérios, na tentativa de resguardar técnicas e processos de uma comunidade ou grupo. Para uma abordagem detalhada da política de patrimônio imaterial em nível nacional e das legislações estaduais, ver Cavalcanti e Fonseca, 2008. 
disseminam pela heterogeneidade do tecido social. Ocorre, assim, como sugere Arantes (2010, p. 56), o fortalecimento da "autoridade intelectual dos reivindicantes", definindo "estratégias e prioridades relativas a seu desenvolvimento cultural". Como contraface deste processo, a política de registro de bens imateriais também pode implicar o incremento da circulação e consumo, quando explorada pela atividade turística e outros setores da economia. Arantes (2004, p. 12) problematiza sua captura pela indústria cultural, que torna certas práticas oriundas de registros patrimoniais "indissociáveis do complexo cenário emergente que articula cultura e política ao mercado e ao entretenimento". Ainda segundo o autor, existe uma preocupação constante dos especialistas que analisam os pormenores da patrimonialização como política de Estado, já que esta pode ocasionar mudanças nos estilos de vida e nas fronteiras simbólicas, além de produzir "sentidos de lugar". Constituem, assim, "marcadores de identidade" (ARANTES, 2004, p. 13), como parece ser o caso de Maragojipe, em que a circulação das máscaras carnavalescas opera na projeção da identidade local, uma vez que esta constitui-se como um marco da memória, da tradição e da autenticidade da festa.

Agregada a um plano de salvaguarda para a "preservação" das tradições, a política de patrimonialização do carnaval de Maragojipe parece ampliar o horizonte daquilo que Cunha (2009) já havia caracterizado como "cultura com aspas", ativando e disseminando processos de reflexividade na diversidade do mundo social ${ }^{11}$. Afinal, as máscaras sempre estiveram presentes no carnaval do lugar; são parte da cultura local, que compreende também a elaboração de fantasias. Mas uma ação governamental traçada com o intuito de revitalizar o carnaval e as máscaras implica em ações deliberadas de mudança. A seguir apresentaremos algumas dimensões e consequências desse processo.

\section{a) Esgotamento da festa de trio e início da transformação}

Conforme indicado acima, a partir dos anos 1980 o trio elétrico ganhou destaque em Maragojipe. Surgiram blocos nesse período que reproduziam o figurino dos foliões do carnaval em Salvador, replicando um modelo que perdura na capital até os dias atuais, embora já dando sinais de desgaste (evidenciado no crescente estímulo a blocos tradicionais e maior pluralidade de expressões carnavalescas). Em Maragojipe, apesar de outras manifestações carnavalescas, o trio elétrico chamava atenção pelo alto volume de suas caixas de som e pela força da axé music.

No início dos anos 2000 o carnaval era tomado por foliões uniformizados com camisetas de blocos que seguiam trios elétricos. Mas o sucesso não era o mesmo do carnaval de Salvador e esse modelo de festa passou a ser questionado. Foi nesse período que começou a circular informações de que a gestão municipal estaria determinada a não mais patrocinar a festa,

11 Tamaso (2018) destaca a intensa reflexividade na relação entre a prática antropológica e as políticas de patrimonialização decorrentes das múltiplas formas de inserção desses profissionais. Daí a pesquisadora perguntar, provocativamente, de que forma é possível sair dessa agenda do Estado e pautar, de forma mais criativa, novos desafios da patrimonialização. 
conforme esclarece Pedro Arcanjo, que viria a ser Secretário de Cultura daquela cidade e idealizador da patrimonialização do carnaval local.

No ano de 2005 houve mudança na gestão municipal e Pedro Arcanjo, novo Secretário de Cultura, buscou incentivar a tradição dos mascarados e outros fantasiados, que vinha diminuindo. O então secretário idealizou o projeto de patrimonialização inspirado na Festa de Santa Bárbara, realizada em Salvador, no mês de dezembro, que estava em via de ser patrimonializada. Naquele período, reivindicava-se o reconhecimento oficial por parte do Estado ${ }^{12}$ de algumas festas populares (Santa Bárbara), saberes tradicionais (Pano da Costa), e rituais religiosos (Irmandade da Boa Morte).

O projeto da Secretaria de Cultura de Maragojipe passava, então, pela garantia de uma salvaguarda do carnaval que mantivesse a tradição das máscaras. Nesse intento, já no ano de 2005 foi construído um coreto na praça central do município e instituído o concurso de máscaras e fantasias para fomentar a criatividade do folião ${ }^{13}$. Arcanjo tomou para si a responsabilidade do processo de patrimonialização, que tinha como política a instauração de um Museu do Carnaval, espaço que tornaria permanente a simbologia do evento.

A viabilização desse projeto passou por uma "reinvenção" dos mascarados (e fantasiados em geral), pois o palco-coreto criado era justamente para associar a iniciativa da patrimonialização a uma nova configuração da festa, que implicava o deslocamento dos trios elétricos para um circuito "paralelo", próximo ao palco-coreto, e a elaboração de novas diretrizes para formalizar um reavivamento dos mascarados. De fato, a partir de 2006, segundo interlocutores, houve um aumento significativo do número de mascarados e fantasiados, não apenas concorrendo ao concurso regulamentado, mas também formando "grupos de mascarados" percorrendo as ruas com fantasias sofisticadas.

\section{b) A iniciativa de um gestor e a "campanha" na cidade}

O processo de patrimonialização se iniciou após a realização de audiência pública na Casa de Cultura - onde a Secretaria de Cultura está situada - para que a população da cidade tivesse entendimento do projeto que surgia naquele ano de 2006. Para que os maragojipanos aderissem à iniciativa, um caderno de assinaturas foi colocado na porta de entrada do edifício, na intenção de ser anexado aos documentos enviados ao IPAC. Como o "caderno" não surtiu o

12 O IPAC é responsável pela articulação com comunidades que buscam preservar seus patrimônios culturais, realizando juntamente a estas, políticas de salvaguarda. Os procedimentos para efetivação dessas políticas são as mesmas reconhecidas pelo Decreto no 3551/2000 que instituiu o Registro de Bens Imateriais. Informações sobre os bens patrimonializados pelo IPHAC encontram-se disponíveis em http://www.ipac.ba.gov.br/publicacoes-para-download/cadernos. Acesso em: 18 mar. 2016. Problematizando as relações entre patrimonialização e turismo nas políticas estaduais, Santos (2017), destaca que o Ipac desde o seu início, nos anos de 1960, estabelece forte relação entre preservação do patrimônio e incremento do turismo, em consonância com políticas públicas nacionais. A hegemonia desta instituição no estado aparou arestas e conferiu celeridade à implementação da política de patrimônio imaterial.

13 Importante notar que apesar da realização do concurso em 2005, a Secretaria de Cultura classificou o início do mesmo apenas em 2008, ano da visita dos técnicos do IPAC ao carnaval, conforme veremos adiante. 
efeito desejado, funcionários da secretaria percorreram as ruas do município para arregimentar assinaturas diretamente nas residências. Dois funcionários e um voluntário executaram essa tarefa (em entrevista, um dos funcionários comentou que houve desconfiança por parte de algumas pessoas, que não assinaram por acreditar que se tratava de "politicagem").

Os responsáveis pela coleta de assinaturas passaram, então, a visitar as escolas do município na segunda etapa dessa empreitada, no ano de 2007. Com a colaboração de um grupo teatral de Maragojipe na passagem pelas escolas, o número de assinaturas aumentou. Segundo o funcionário entrevistado, a "consciência da juventude" contribuiu para alavancar o montante de assinaturas, mesmo com alguns professores dificultando o acesso de funcionários e voluntários nas instituições de ensino visitadas, além da não autorização de alguns pais para a participação de seus filhos nesse processo. Nessa ocasião circulou pela cidade um panfleto intitulado "Campanha de solicitação de inscrição do tombamento do carnaval de Maragojipe como bem cultural e imaterial junto ao IPAC e IPHAN", em que constavam informações sobre o caráter "autêntico" da festa, apontando a antiguidade do uso das máscaras, remontando ao Entrudo, além de destacar a importância da patrimonialização do carnaval para o fortalecimento dos valores culturais do município ${ }^{14}$.

Após receber a solicitação e notificar o pedido da Secretaria de Cultura de Maragojipe, o IPAC passou a requerer documentação necessária para a continuidade do processo de registro ${ }^{15}$. Com vistas a garantir o andamento do processo de forma regular e regimental, foi criado um Conselho Gestor em Maragojipe, que contou com um representante do IPAC no ano de 2007, e estabelecido um convênio entre a administração municipal e o IPAC para suporte técnico. Concluídos os procedimentos burocráticos que envolviam a pré-patrimonialização, foram enviados técnicos à cidade a fim de iniciar trabalho de campo para elaboração do inventário.

Assim, apesar das dificuldades, os esforços garantiram a presença de uma equipe do IPAC em pleno carnaval de 2008 para avaliar a viabilidade do registro da festa. Uma grande movimentação na cidade permitiu que se organizasse um "caprichado" carnaval naquela ocasião, buscando "causar boa impressão" aos visitantes, segundo alguns interlocutores (nesse período, Arcanjo não era mais o secretário).

A equipe do IPAC presente em Maragojipe durante o carnaval de 2008 contava com uma antropóloga, um fotógrafo e o gerente do departamento responsável pela coordenação de políticas de salvaguarda do órgão. Durante a visita, foram documentados os foliões mascarados, coletados depoimentos, obtidas fotografias pertencentes a acervos pessoais, tudo para estabelecer

14 Segundo interlocutores, a não realização de audiências públicas ao longo do processo teria motivado a suspeita de muitos moradores. Um funcionário da Casa de Cultura afirmou que "houve apenas uma única reunião, mas sem ata para ratificar o encontro". Essa reunião não chegou a ter grande divulgação e não foi disponibilizado material informativo em larga escala para esclarecer os moradores da cidade.

15 A notificação é publicada, passando, a seguir, por uma apreciação do Conselho Estadual de Cultura - órgão ligado à Secretaria de Cultura da Bahia (SECULT), de caráter consultivo, que contribui para a política estadual de cultura. Analisada a documentação exigida, o IPAC inicia os procedimentos para encaminhar a equipe técnica responsável por avaliar o bem a ser inventariado. 
relações entre o carnaval a ser patrimonializado e a memória festiva dos carnavais de outras gerações. Preparado o dossiê, acrescido de pesquisa histórica sobre a cidade e textos sobre o carnaval, este passou a ser avaliado por uma equipe da Câmara do Patrimônio Histórico, Artístico, Arqueológico e Material, formado por membros do Conselho Estadual de Cultura. Feita a avaliação, o dossiê foi encaminhado à SECULT e depois à Casa Civil, que despachou o parecer para ser publicado no Diário Oficial do Estado. O Decreto Estadual no 11.449/2008 foi sancionado pelo então governador Jaques Wagner, no ano de 2009.

Embora o processo de patrimonialização tenha obtido êxito, até o momento não foi instaurado o Museu do Carnaval como parte da política de salvaguarda. Em conversas com funcionários da Secretaria de Cultura, estes mencionaram a alta rotatividade de smecretários na pasta como entrave para que o museu se efetive. De Pedro Arcanjo até o ocupante que organizou o carnaval de 2016, foram oito secretários. Alguns deles não mostravam interesse na patrimonialização, segundo relatos.

\section{Ambiguidades do carnaval patrimonializado}

O ideário em torno do patrimônio refere-se não somente a sua dimensão contemporânea, mas também histórica. No entanto, apesar das transformações da festa, a noção de patrimônio cultural, que ainda encontra eco na "retórica da perda" (GONÇALVES, 2012), tende a buscar nas manifestações de mascarados e fantasiados o carnaval que "sempre fizeram". Veremos, no entanto, que as mudanças são promovidas no âmbito do processo mesmo da patrimonialização.

O carnaval de Maragojipe se consolidou com as manifestações carnavalescas que datam de muitos anos, mas também das novas formas de se fazer o carnaval. Assim é que, em janeiro de 2005, foi construído o palco-coreto para a realização de um concurso e de apresentações musicais. Arcanjo mencionou que essas ações faziam parte de um programa de reestruturação da festa, mas novos desdobramentos não cessaram de acontecer, como a sofisticação crescente das máscaras inspiradas no carnaval veneziano, fator de preocupação apontado pelo ex-secretário. Grupos "padronizados" de mascarados tiveram grande ascensão nos últimos carnavais, intensificando uma certa elitização na confecção das máscaras e fantasias, especialmente visível na participação no concurso. Arcanjo aponta que esse processo ocorria antes mesmo do registro da festa: à medida que se evidenciava a possibilidade da patrimonialização, houve um incremento nas fantasias. Ele ressaltou, ainda, que o concurso gerenciado pela Secretaria de Cultura naquele ano de 2005 deveria servir de incentivo à criatividade, e não para estimular a estética requintada. No entanto, ele pondera que a própria prefeitura teria motivado essas transformações ao divulgar imagens de mascarados com a estética veneziana. A realização do concurso pode ter induzido alguns foliões a "aprimorarem" as máscaras e fantasias? Arcanjo acredita que essa política desestimulou a confecção de trajes mais simples no concurso, excluindo, assim, os foliões de baixa renda, que transitam pela cidade, mas sem atrair a atenção dos flashes das máquinas fotográficas, que se 
dirigem para os mascarados mais vistosos, que normalmente desfilam em grupos. Como ele esclarece:

A própria prefeitura coloca outdoors com essas máscaras de Veneza porque as fantasias mais criativas são críticas, querem esculhambar a realidade e isso fica escondido porque as máscaras mais sofisticadas chamam mais atenção, mas fáceis de ser compreendidas com referência europeia. E o crescimento dessas máscaras podem inibir a participação de pessoas mais pobres e mais humildes. O menino pega a roupa da irmã pra se fantasiar de Xuxa, pega uma peruca e escuta "o que você vai fazer com essa fantasia lá? Todo mundo com fantasia cara, chamativa e você com esse negócio?". Então cria a dimensão que essas fantasias são inferiores. E o povo vai ficando de fora, se sente excluído.

As transformações no carnaval patrimonializado também se manifestam na sociabilidade dos grupos de brincantes. No Caderno do IPAC (2010, p. 40) é feita uma menção à circulação dos mascarados, indicando que na década de 1950 estes costumavam adentrar às residências. No entanto, vários interlocutores mencionaram que, no passado, esse costume não era tão disseminado como atualmente, ou seja, as visitas eram esporádicas, fazendo com que os mascarados permanecessem mais tempo nas ruas ao invés de nos espaços privados. Como destaca um interlocutor:

“[...] 8h da manhã já tinha careta na rua. Hoje você não vê. Se você vê, é um garoto que não tem paciência de ficar em casa. Só depois de $11,12 \mathrm{~h}$ você vê. E agora aprenderam esse negócio de concentração. Se junta, vai na casa de um, dois, fica lá, bebe, muitos ficam logo "bêbo", se perde do grupo".

A percepção de que os mascarados têm circulado pelas ruas mais tarde é amplamente partilhada. Essa prática pode ter se acentuado após o palco-coreto, local da festa patrimonializada, tornar-se definitivo, desenvolvendo o gosto pela "apreciação" em vez da participação na festa. Da mesma forma, as charangas que outrora desfilavam, atualmente se apresentam no palco, contribuindo para a redução da circulação de foliões. Como não se acompanham mais as charangas e outros grupos pelas ruas, atualmente os participantes tendem a ficar menos tempo nos locais da festa. Além disso, considerando que a programação tem início às 14h, nesse horário ainda há poucas pessoas nas ruas devido ao forte calor do verão maragoijipano ${ }^{16}$. Enfim, certas características que conferiam dinamismo à festa - grupos de mascarados seguindo charangas e percorrendo as ruas do município - já não estão mais presentes.

Uma inovação que ocorreu no carnaval de 2015 foi a contratação, por parte da prefeitura, de um grupo de senhoras vindas de Salvador para desfilar acompanhadas de uma batucada. Esse

16 O circuito patrimonializado "convive" com o circuito "paralelo", com um palco situado na praça matriz, atrás da Igreja de São Bartolomeu, onde se apresentam atrações externas à cidade. A área à frente do palco é mais ampla, comportando mais foliões que à frente do palco-coreto. Entre domingo e terça-feira, grupos de samba de roda se apresentam nesse palco a partir das $13 \mathrm{~h}$. 
episódio desencadeou controvérsias, com vários interlocutores mostrando-se preocupados com as sucessivas interferências do poder público nos rumos da festa. Nesse mesmo ano, a prefeitura passou a cadastrar os grupos de mascarados. A então secretária de cultura do município, Priscila Mendes, relatou, em entrevista:

Nós vamos ver o resultado desse cadastro para ações mais aprofundadas e direcionadas. A gente precisa profissionalizar o carnaval. A gente quer conhecer os grupos, até mesmo pra dar uma visibilidade maior. Às vezes o grupo ganha o concurso e não participa de nenhuma ação fora. Se a gente tem uma pauta de diálogo, um cronograma de ações, a gente mostra que estamos (sic) tentando uma articulação com eles, pois eles fazem parte do processo.

\section{Festa e cultura: a "exportação" dos mascarados}

Após o registro do carnaval, em 2009, como Patrimônio Imaterial da Bahia, a festa teve maior visibilidade ${ }^{17}$. A gestão municipal contribuiu decisivamente para esse sucesso com a "institucionalização" de algumas atividades que ocorriam de forma espontânea, como a propaganda do carnaval durante o cortejo da Lavagem do Bonfim, em Salvador. Em 2016, pudemos acompanhar, desde Maragojipe, os preparativos para o comparecimento na Lavagem: um ônibus saiu da cidade às $4 \mathrm{~h} 30$ com cerca de 30 pessoas uniformizadas e "mascaradas" para esta finalidade, além dos músicos de uma charanga que animava o cortejo. Sem critérios rígidos para entrar no ônibus e nem remuneração para esse evento (a prefeitura se responsabilizou pelo deslocamento e o almoço), os participantes foram com fantasias de carnavais anteriores.

A presença dos mascarados na festa da lavagem do Bonfim nesse formato organizado e patrocinado pela prefeitura teve início em 2005. A assiduidade na Lavagem do Bonfim, desde então, já proporcionou novos convites para os mascarados, como a participação em festas de outros municípios, além da demanda feita pela prefeitura de Salvador, que organizou pela primeira vez, em 2016, um evento pré-carnavalesco chamado "Fuzuê", congregando diferentes manifestações carnavalescas. Naquela edição do evento, os mascarados de Maragojipe foram a única atração oriunda de outra cidade ${ }^{18}$.

Outros acontecimentos evidenciam a visibilidade do carnaval de Maragojipe. Em 2011, a Escola de Samba Portela homenageou a Bahia como tema do seu desfile. O carnavalesco Paulo Menezes, que conheceu o carnaval de Maragojipe através da então primeira-dama da Bahia,

17 Desde então, a Secretaria de Cultura do município distribuiu panfletos propagandeando o carnaval local com informações sobre a festa (breve histórico, manifestações populares e ilustrações dos mascarados). Houve também a colocação de outdoors em estradas na região de Salvador com propaganda do carnaval.

18 As atrações foram: Ganhadeiras de Itapoan, Bloco do Jacu, Pierrot de Plataforma, Bloco Saco Cheio, Paroano Sai Milhó, Afoxé CorinEfan, As Kuviteiras, Comanches do Pelô, Os Mutantes, além dos Mascarados de Maragojipe. Disponível em <http:/g1.globo.com/bahia/carnaval/2016/noticia/2016/01/conheca-atracoes-do-pre-carnaval-de-salvador-com-fuzue-e-furdunco.html>. Acesso em: 05 jul. 2016. 
Fátima Mendonça, convidou os mascarados a comporem uma ala da Escola na Marquês de Sapucaí, apresentando-se num carro alegórico que retratava o Pelourinho, com sua arquitetura. Nessa ocasião, os mascarados também participaram de uma festa de reinauguração da quadra da Portela ${ }^{19}$. Em 2010, o carnaval maragojipano também foi objeto de exposição fotográfica no Shopping Salvador, localizado na capital baiana: "Maragojipe - Carnaval dos Bons Tempos" foi iniciativa da prefeitura e contou com o apoio da Secretaria de Cultura da Bahia (SECULT) ${ }^{20}$.

Em 2011, a presença dos mascarados se estendeu à França, na Lavagem de La Madeleine, em Paris. Inspirado na Lavagem do Bonfim, o evento compreende um cortejo que se dirige à Igreja La Madeleine, seguido da lavagem das escadarias. A Lavagem, que ocorre no mês de setembro $^{21}$, conta com o apoio da Bahiatursa, sendo organizado desde 2002 pelo produtor cultural Roberto Chaves, natural do município baiano de Santo Amaro da Purificação. Naquele ano houve também a participação do cantor e compositor Carlinhos Brown, ocasião em que o evento comemorou 10 anos. A festividade teve repercussão na mídia baiana, com reportagens na TV Bahia e no jornal Correio da Bahia (FANTINEL, 2014). Desde 2013, o carnaval de Maragojipe também participa da Micareta realizada no município de Feira de Santana, que conta com a presença dos mascarados, elemento mais característico da festa (a Micareta acontece em abril) $)^{22}$.

A participação dos mascarados em eventos para além do carnaval e da cidade tem fortalecido sua simbolização como referência cultural. As gestões municipais vêm explorando essa possibilidade há alguns anos, inclusive no âmbito das festividades municipais, como na popularíssima Festa de São Bartolomeu, que acontece em agosto. Como esclarece nosso interlocutor, professor "Bibito":

\begin{abstract}
O pregão da festa de São Bartolomeu era anunciado por mascarados. O pregão é uma manifestação cultural que faz o apregoamento da proximidade da festa. Todo primeiro sábado de julho o cara saía pra pregar na feira e lia o que se pretendia realizar em agosto, anunciando a programação oficial da festa sendo dada no segundo domingo de agosto, que era o bando anunciador. De início, saía uma pessoa da irmandade fazendo esse pregão. Depois, o espírito do carnaval atingiu esse pregão com a presença desses mascarados. Eram 4 ou 5 mascarados montados a cavalo tocando trompete, essas coisas. Isso foi até bem pouco tempo quando tiraram os cavalos em função de política ambientalista, não maltratando os animais.... Depois, isso foi sendo papel da comissão da festa. Mas tô querendo resgatar esses mascarados fazendo o pregão a pé! Tiraram os cavalos, tiraram os mascarados. Deixa os mascarados! Só nesse evento que via a presença dos mascarados. Lembrando que os mascarados saiam no pregão de julho e o bando anunciador saia em agosto, sem máscaras.
\end{abstract}

19 Disponível em $<$ https://www.youtube.com/watch?v=WrwM4jlOLc4 $\geq$. Acesso em: 05 jul. 2016.

20 Disponível em <http://www.reconcavonews.com/2010/01/mostra-fotografica-leva-o-carnaval-de.html $>$. Acesso em: 05 jul. 2016.

21 Disponível em <http://www.cultura.ba.gov.br/2012/09/5095/Carnaval-de-Maragojipe-e-destaque-na-Lavagem-de-La-Madeleine-em-Paris-.html >. Acesso em: 06 jul. 2016.

22 Disponível em <http://www.micaretafeira.com.br/noticia/982/atracoes-definidas-no-espaco-charles-albert>. Acesso em: 05 jul. 2016. 
Em 2016 a prefeitura de Maragojipe apresentou os mascarados como atrativo da cidade no " $3^{\circ}$ Salão Baiano de Turismo", evento de negócios organizado pela Bahiatursa no mês de maio, em Salvador. A autarquia promoveu o encontro no Centro de Convenções com a participação dos municípios das 13 zonas turísticas da Bahia, alocados em stands ${ }^{23}$. Os mascarados também estiveram presentes no espetáculo musical "Maragojipe Canta Seus Filhos", patrocinado pela prefeitura, realizado na cidade e, por vezes, em outras localidades. Em entrevista conosco, o exsecretário de cultura da cidade, Luis Carlos Brasileiro, esclarece como se originou esse evento:

Existia um projeto chamado "Sonho da Cidade" e tentei dar uma dinamizada e pegava artistas de Maragojipe para cantar, convidei Iracema, Tatai, Nau Franzini, Dica... todos artistas de Maragojipe. Circulamos nos distritos durante três anos e durante uma festa de agosto, que não me lembro o ano, esses artistas se apresentaram com uma orquestra e ficou muito bom. E isso foi agregando ao "Sonhos da Cidade". E aí Ataliba (ex-prefeito) me deu a ideia de adicionar esses artistas no projeto "Maragojipe Canta Seus Filhos" que foi um movimento que se direcionou também pro carnaval aqui de Maragojipe. Em 2013, tivemos a ideia de levar esse projeto ao Pelourinho com os artistas de Maragojipe cantando músicas de carnaval, pois estávamos ali divulgando o carnaval de Maragojipe em outro polo, no caso Salvador. A ideia era chamarmos a imprensa, os maragojipanos que moram em Salvador, e valorizar os artistas. E a gente levou um grupo de mascarados - que é nosso cartão postal".

Pode-se depreender, a partir dessas diferentes iniciativas, os desdobramentos da patrimonialização do carnaval, gerando novos projetos com enfoque na figura do mascarado como "um cartão de visitas", uma imagem de reconhecimento da cidade para além do contexto local e regional. Impulsionados pelo registro da festa, a sociedade civil de Maragojipe vem articulando propostas de incentivo à cultura do município. Paulo Cézar Fernandes, coordenador da Associação de Sambadores e Sambadeiras de Maragojipe, produziu o projeto "Maragojipe Circulando com o Samba de Roda e os Mascarados". A inciativa tem como foco o samba-de-roda, mas agrega os mascarados nas suas exibições. Em entrevista, ele detalha aspectos da iniciativa:

Foi um projeto criado por mim em 2012 com auxílio do Fundo de Cultura do Estado chamado "Maragojipe Circulando com o Samba de Roda e os Mascarados" percorrendo algumas cidades. Faz um ano que começamos, dia 28/01/14 começando aqui na Casa de Cultura de Maragojipe e fomos pra Saubara, Santo Amaro, e Cachoeira. O marco foi a apresentação do samba de roda e dos mascarados. Minha ideia foi uma apresentação fora daqui de Maragojipe. A gente era recepcionado por um samba de roda de lá e depois tocava o nosso e entre essas apresentações entravam os mascara$\operatorname{dos}^{24}$.

23 Disponível em <http://bahia.com.br/noticias/iii-salao-baiano-de-turismo-e-apresentado-ao-trade/>. Acesso em: 06 jul. 2016.

24 Mais detalhes no site <www.maragojipecirculando.com.br.>. Acesso em: 10 nov. 2018. 
Outras iniciativas de promoção do carnaval ocorreram, contando com apoio e convênios do Governo da Bahia, através da SECULT e Bahiatursa, como os registros das participações de mascarados nas cidades de Lisboa, Madri, e Paris ${ }^{25}$. Segundo os membros da referida associação, estes teriam sido os únicos representantes brasileiros na ocasião, sugerindo que a máscara de Maragojipe vem ganhando novos significados fora do contexto da festa. Nessa mesma direção temos as apresentações de artistas de Maragojipe em Salvador, com a realização do "Carnamaragojipe", no ano de 2013, que contou com a presença de músicos da cidade acompanhados da Orquestra Popular de Maragojipe, mostras de vídeos e charangas percorrendo praças do Pelourinho com a participação de dezenas de mascarados.

Nossos interlocutores também destacam outro importante momento, para além das iniciativas aqui mencionadas, que foi o VIII Festival Internacional da Máscara Ibérica, em maio de 2013, na capital portuguesa. A AMMA (Associação dos Músicos de Maragojipe) recebeu um convite dos organizadores, a EGEAC (Empresa de Gestão de Equipamentos e Animação Cultural da Câmara Municipal de Lisboa), que foi feito a três artesãos de Maragojipe para apresentarem seus trabalhos. Estavam na Mostra os artesãos Renato, "Barbudo" e Márcia. Renato e Márcia participaram do evento com roupas e fantasias, enquanto "Barbudo" ficou responsável pela exposição de suas máscaras. Um folder encontrado nos arquivos da AMMA relata a participação de "Barbudo" em um programa de uma TV lisbonense, com a seguinte chamada: "No dia 10/05/13, o artista maragojipano Memeu Barbudo foi entrevistado ao vivo no Programa "Praça da Alegria", transmitido em rede nacional pela RTP - Rádio e Televisão de Portugal".

\section{Considerações finais}

Apontamos, neste artigo, alguns dilemas e desdobramentos da patrimonialização do carnaval de maragojipe, ao mesmo tempo fazendo e transformando a festa no tempo e no território. Seguindo ideias de Perez (2012) e Tavares (2012) sobre os agenciamentos da festa para além da festa, os símbolos fazem e transformam a cultura, desencadeando "vazamentos" (INGOLD, 2015) entre dimensões supostamente contidas: a simbólica e a material. Ao invés de dicotomias, podemos seguir os materiais de que são feitas as políticas de patrimonialização, com o "surgimento" de tradições contagiando as transformações; como os materiais das máscaras, que se abrem para o tempo do carnaval e ao mesmo tempo para a sua dissolução na cultura.

Mas a festa pode se desdobrar em patrimônio sem riscos? Para Gonçalves (2005, p. 20), a categoria patrimônio pode auxiliar na visibilização de dimensões da vida social “[...] uma vez que liminarmente situada entre o passado e o presente, entre o cosmos e a sociedade, entre a cultura e os indivíduos, entre a história e a memória." Sua vitalidade residiria na própria ambiguidade

25 Como destacado no site http://www.ipac.ba.gov.br/noticias/europa-conhece-carnaval-de-maragojipe Acesso em: 10 nov. 2018. 
do conceito, sendo, portanto, perigosas as tentativas de sua contenção por meio de políticas que buscam enrijecer fronteiras.

Transitando nessa ambiguidade, vimos que os desdobramentos da patrimonialização apresentam dois movimentos. O primeiro está situado nas transformações "por dentro" da festa, com consequências controversas para a sua vitalidade, como a diminuição da circulação dos brincantes pelas ruas e a produção de hierarquias entre as fantasias elitizadas dos concursos e os demais fantasiados, numa festa que, conforme destaca Roberto DaMatta (1979), dramatiza a inversão das normas e o igualitarismo ${ }^{26}$. Esse processo também se distancia muito das observações de Arantes (2010), ao contextualizar as políticas de preservação do patrimônio como uma iniciativa compartilhada entre a comunidade e seus agentes políticos. Sabemos que a construção de ações que irão legitimar esse processo é uma constante negociação, com práticas sociais oriundas dos diversos setores comunitários, e que sua participação nas esferas políticas fortalece a autoridade intelectual e legitima o saber local, pois decidem em conjunto com os agentes do Estado "estratégias políticas e de prioridades relativas a seu próprio desenvolvimento cultural" (ARANTES, 2010, p. 56).

O segundo movimento, centrífugo, leva o carnaval para além da festa. O carnaval de Maragojipe se transforma, mobilizando a figura do mascarado que se funde à própria imagem da cidade; mas sua aparição em outros contextos não o aprisiona a uma característica performática da festa apenas. O mascarado também faz política cultural imiscuindo-se por outras dimensões da esfera pública. A confluência entre carnaval e eventos culturais, consolidando-o como valor da cidade explicita o imbricamento entre interesses governamentais, ações de entidades da sociedade civil e a população em geral na conformação de políticas públicas.

No início do século XX, quando os "caretas" surgiram no carnaval de Maragojipe, foi se estabelecendo maneiras e formas de brincar que os consolidaram como elemento central dos festejos nessa cidade. Ranchos, Ternos, e cordões surgiram e desapareceram; o trio elétrico, com frevos potentes entoados ao som das guitarras; blocos privativos desfilando pelas ruas ao som do axé music, principal ritmo do carnaval soteropolitano; palcos de tamanho considerável ostentando shows de diversos artistas. Foram muitos os momentos em que Maragojipe "recebia" tendências e modismos vindos de outras cidades, especialmente de Salvador, mas sempre se manteve a presença dos "caretas" e sua euforia. Durante o processo de patrimonialização do carnaval os maragojipanos fortaleceram o mascarado, gerando novas conformações estéticas. Afinal, a idealização da patrimonialização da festa passou pela preocupação com o declínio de sua presença. O carnaval foi patrimonializado, mas a referência simbólica da festa concentrou-

26 As festas carnavalescas podem ser compreendidas como rituais de inversão de status social. Segundo Bakhtin (2008) o carnaval situa-se na fronteira entre a arte e a vida, cujo potencial libertário já vigorava na Idade Média. "O carnaval era uma espécie de liberação temporária da verdade dominante e do regime vigente, de abolição provisória de todas as relações hierárquicas, privilégios, regras e tabus" (p. 8). A festa carnavalesca ganha densidade interpretativa, no Brasil, por meio dos trabalhos de Roberto DaMatta que compreende o carnaval como subversão da ordem, articulando "categorias e papeis sociais que no cotidiano são segregados." (1979, p. 80). 
se na figura do mascarado, que contribuiu decisivamente para legitimar esse processo de reconhecimento. A simbologia do mascarado é tão forte que mesmo havendo "caretas" em outros municípios vizinhos, muitos habitantes dessa região da Bahia se encaminham até Maragojipe para curtir a festa por lá. A promoção do carnaval visibilizando os mascarados - a maioria com suas "nariguetas" - propicia produções imagéticas, reportagens, textos, documentários, sempre com estes à frente de outras expressões festivas do carnaval de Maragojipe, como as charangas e fantasiados, evidenciando a "autenticidade" dessa figura para os maragojipanos.

Pode-se, finalmente, perguntar, como fez Gonçalves (2005), qual seria a vantagem de considerar algo como patrimônio? No caso apresentado neste trabalho, o carnaval, com suas máscaras, leva o bem patrimonializado para dentro e para além da festa e da cidade, visibilizando a potência das transformações que os símbolos carregam. Essas são características da cultura autêntica, aquilo que não é objetificado. As políticas de patrimônio cultural deveriam sempre ter em conta esses cuidados.

\section{Referências}

ABREU, Regina; LIMA FILHO, Manuel. A antropologia e o patrimônio cultural no Brasil. In: BELTRÃO, Jane Felipe; ECKERT, Cornelia; FILHO, Manuel Lima. Antropologia e Patrimônio Cultural. Blumenau: Nova Letra, 2007. ARANTES, Antônio. O patrimônio imaterial e a sustentabilidade de sua salvaguarda. Resgate, Campinas, v. 12, n. 1, p. 11-18, 2004. Disponível em: file:///C:/Users/fatta_000/Downloads/8645608-18329-1-PB.pdf. Acesso em: 25 jul. 2018.

A salvaguarda do patrimônio imaterial no Brasil. In: BARRIO, Angel; MOTTA, Antonio; GOMES, Mario (Orgs.) Inovação cultural, Patrimônio e Educação. Recife: Fundação Joaquim Nabuco/Editora Massangana, 2010. p. 53-63. Disponível em: https://s3.amazonaws.com/academia.edu.documents/7038878/PatrimonioCulturaleaQuestaoEtnicaRN.pdf?AWSAccessKeyId=AKIAIWOWYYGZ2Y53UL3A\&Expires=1532549080\&Signature=rhTXPJw0SRVHxBs2JGZP5VxKKno\%3D\&response-content-disposition=inline\%3B\%20filename\%3DPatrimonio_cultural_e_questao_etnica_no.pdf\#page=52. Acesso em: 25 jul. 2018.

BAHIA. Cadernos do IPAC. Carnaval de Maragojipe. Salvador: Gráfica Qualicopy, 2010.

BAKHTIN, Mikhail. Cultura Popular na Idade Média: O Contexto de François Rabelais. Tradução de Yara Frateschi Vieira. São Paulo: Hucitec; Brasília: Universidade de Brasília, 2008.

BRASIL . Censo 2010. Rio de Janeiro: IBGE, 2010.

BRASIL. Constituição da República Federativa do Brasil de 1988. Disponível em: < http://www.planalto. gov.br/ccivil_03/Constituicao/Constituiçao.htm>. Acesso em: 25 jul. 2018.

BRASIL. IBGE. Enciclopédia dos Municípios Brasileiros. Rio de Janeiro: IBGE, 1958.

CARDOSO, Carlos. Máscaras e folia: patrimonialização do carnaval em Maragojipe. 2016. 99 f. Dissertação (Mestrado em Antropologia) - Programa de Pós-graduação em Antropologia, Universidade Federal da Bahia, Salvador. CASCUDO, Luis da Câmara. Dicionário do Folclore Brasileiro. São Paulo: Atlas, 2001.

CAVALCANTI, Maria Laura; FONSECA, Maria Cecília. Patrimônio Imaterial no Brasil: legislação e políticas estaduais. Brasília: Unesco/Educarte, 2008.

CONCEIÇÃO, Erick; CASTRO, Janio. O carnaval de Maragogipe-ba como patrimônio imaterial: Uma leitura a partir da geografia cultural. Caminhos de Geografia, Uberlândia-MG, v. 15, n. 50, p. 114-126, 2014.

CUNHA, Manuela Carneiro da. Cultura com aspas. Rio de Janeiro: Cosac Naiff, 2009. 
Censo 2010. Rio de Janeiro: IBGE, 2010.

DAMATTA, Roberto da. Carnavais, malandros e heróis: para uma sociologia do dilema brasileiro. Rio de Janeiro: Rocco, 1979.

FANTINEL, Caroline. “Oropa, França e Bahia”: Lavagem de La Madeleine, uma folia mestiça. 2014. 112 f. Dissertação (Mestrado em Cultura e Sociedade) - Programa Multidisciplinar de Pós-graduação em Cultura e Sociedade, Universidade Federal da Bahia, Salvador.

FRY, Peter; CARRARA, Sérgio; MARTINS-COSTA, Ana. Negros e brancos no carnaval da Velha República. In: REIS, João. Escravidão e Invenção da Liberdade. São Paulo: Ed. Brasiliense, 1988. p. 232-263.

GONÇALVES, José Reginaldo. As transformações do patrimônio: da retórica da perda à reconstrução permanente. In: TAMASO, Isabela; LIMA FILHO, Manuel (Orgs.). Antropologia e patrimônio cultural: trajetórias e conceitos. Brasília: ABA, 2012. p. 59-73.

Ressonância, materialidade e subjetividade: as culturas como patrimônios. Horizontes antropológicos, Porto Alegre, v. 23, n.11, p. 15-36, jan./jun. 2005.

INGOLD, Tim. Trazendo as coisas de volta à vida: emaranhados criativos num mundo de materiais. Horizontes antropológicos, Porto Alegre, v.18, n. 37, p. 25-44, jan./jun. 2012.

LATOUR, Bruno. Reagregando o social: uma introdução à teoria do ator-rede. Salvador: Edufba, 2012.

MORAES FILHO, Melo. Festas e Tradições Populares no Brasil. Rio de Janeiro: Itatiaia, 1979.

MOURA, Milton. Êxtase e euforia: Um binômio estratégico para a compreensão histórica do carnaval contemporâneo. Observatório Itaú Cultural, São Paulo, n. 14, p. 33-38, mai. 2013, nº 14. Disponível em <http://d3nv1jy4u7zmsc.cloudfront.net/wp-content/uploads/2013/09/Revista-Observat\%C3\%B3rio-14.pdf>. Acesso em: 12 fev. 2016. PEREZ, Léa Freitas. Festa para além da festa. In: PEREZ, Léa; AMARAL, Leila; MESQUITA, Wania (Orgs.). Festa como perspectiva e em perspectiva. Rio de Janeiro: Garamond Universitária, 2012. p. 21-42.

RAMOS, Cleidiana. Festa de verão em Salvador. Um estudo antropológico a partir do acervo documental do jornal A Tarde. 2017. 362 f. Tese (Doutorado em Antropologia) - Programa de Pós-graduação em Antropologia, Universidade Federal da Bahia, Salvador.

ROCHA, Ana Luiza Carvalho da; ECKERT, Cornelia. Cidade e suas crises, o patrimônio pelo viés da memória. In: BARRIO, Angel; MOTTA, Antonio; GOMES, Mario (Orgs.). Inovação cultural, Patrimônio e Educação. Recife: Fundação Joaquim Nabuco/Editora Massangana,2010.p. 188-197. Disponível em:https://s3.amazonaws.com/academia.edu.documents/7038878/PatrimonioCulturaleaQuestaoEtnicaRN.pdf?AWSAccessKeyId=AKIAIWOWYYGZ2Y53UL3A\&Expires=1532549080\&Signature $=$ rhTXPJw0SRVHxBs2JGZP5VxKKno\%3D\&response-content -disposition=inline\%3B\%20filename\%3DPatrimonio_cultural_e_questao_etnica_no.pdf\#page=52. Acesso em: 25 jul. 2018.

SANTOS, Magno. Polissemias do Patrimônio: políticas públicas estaduais do registro das festas católicas (Bahia, Sergipe e Rio Grande do Norte). Revista Memória em Rede, Pelotas-RS, v. 9, n. 16, p. 43-66, 2017.

SILVEIRA, Wayra. Um natal brasileiro. A produção de sentidos no baile pastoril queimada da palhinha. In: TAVARES, Fátima; BASSI, Francesca (Orgs.). Festas na Baía de Todos os Santos: visibilizando diversidades, territórios, sociabilidades. Salvador: Edufba, 2015. p. 43-64.

TAMASO, Izabela. Quando o campo são os patrimônios: conhecimento e práticas científicas na esfera pública. Revista de Antropologia, São Paulo, v. 61, n.1, p. 60-70, 2018.

TAVARES, Fátima; BASSI, Francesca. Diversidade e invisibilidade festiva na Baía de Todos os Santos. In: TAVARES, Fátima; BASSI, Francesca (Orgs.). Festas na Baía de Todos os Santos: visibilizando diversidades, territórios, sociabilidades. Salvador: Edufba, 2015. p. 255-278. 
.TAVARES, Fátima; . BASSI, Francesca (Orgs.). Festas na Baía de Todos os Santos: visibilizando diversidades, territórios, sociabilidades. Salvador: Edufba, 2015.

Religião, festa e ritual como agenciamentos possíveis. In: PEREZ, Léa Freitas; AMARAL, Leila; MESQUITA, Wania (Orgs.). Festa como perspectiva e em perspectiva. Rio de Janeiro: Garamond Universitária, 2012. p. 119130

2017. A -rograma de Pós-graduação em ntropologianiversidade ederal da ahia

Recebido em: 19/09/2018

Aceito em: 23/10/2018 